\title{
Assessment of Toll-like receptor 2, 4 and 9 SNP genotypes in canine sino-nasal aspergillosis
}

\author{
Elise Mercier ${ }^{1 *}$, lain R Peters ${ }^{2}$, Frédéric Farnir ${ }^{3}$, Rachel Lavoué ${ }^{4}$, Michael Day ${ }^{5}$, Cécile Clercx ${ }^{1}$ \\ and Dominique Peeters ${ }^{1}$
}

\begin{abstract}
Background: The exact aetiology of canine sino-nasal aspergillosis (SNA) is unknown. In man, dysfunction in innate immunity, particularly in the function of pattern recognition receptors, is implicated in the pathogenesis of inflammatory sino-nasal disease and in fungal diseases. Associations between single nucleotide polymorphisms (SNPs) in Toll-like receptors (TLRs) and these diseases have been identified. Similarly, in dogs SNPs in genes encoding TLRs may be important in the pathogenesis of SNA. The aims of the present study were (1) to identify the presence of non-synonymous SNPs in the coding regions of the TLR2, 4 and 9 genes in dogs suffering from SNA, and (2) to investigate the SNP genotypes in dogs with SNA compared with a control population.
\end{abstract}

Results: Direct sequencing of nine dogs of various breeds with SNA revealed two non-synonymous SNPs in the coding region of TLR2, eight in TLR4 and four in TLR9. These non-synonymous SNPs were further evaluated in a case-control study of affected Golden Retrievers, Labrador Retrievers, Rottweilers and Beaucerons. Genotyping was performed using a combination of allele-specific primers and hydrolysis probe assays in 31 dogs with SNA and 31controls. No significant difference in minor allele frequency was identified between these groups, for all studied SNPs, in any of the four breeds.

Conclusions: These findings do not support a role for non-synonymous SNPs in the TLR 2, 4 and 9 coding regions in the pathogenesis of canine SNA, but do not exclude a role for innate immunity in the pathogenesis of the disease.

Keywords: Sino-nasal aspergillosis, Dog, Toll-like receptor gene, Single nucleotide polymorphism

\section{Background}

The sino-nasal mucosa is an important interface with the environment and represents a dynamic system for innate host defence [1]. In addition to providing a barrier to the entry of pathogens, epithelial cells lining the airway are able to recognise pathogen-associated molecular patterns (PAMPs) [2]. Toll-like receptors (TLRs) are situated on these cells and on dendritic cell populations in this location and appear to play crucial roles in the distinction between commensal flora and PAMPs. Single nucleotide polymorphisms (SNPs) within the TLR genes have been reported to impact the immune reaction to microbial antigens, and to be associated with the incidence and outcome of infections [3]. Collectively, the TLRs cover the recognition of a wide variety of

\footnotetext{
* Correspondence: emercier@alumni.ulg.ac.be

'Department of Veterinary Clinical Sciences, Division of Companion Animal Internal Medicine, Faculty of Veterinary Medicine, University of Liège, Sart Tilman, Liège 4000, Belgium

Full list of author information is available at the end of the article
}

pathogens (i.e. viruses, bacteria, parasites and fungi). TLR2, TLR4 and TLR9 are particularly associated with recognition of fungi (e.g. Candida albicans and Aspergillus fumigatus) [4-9], and SNPs in these TLRs have been associated with higher risk of fungal disease in man [10].

In dogs, sino-nasal aspergillosis (SNA) is a cause of chronic rhinitis, and the disease is most often caused by A. fumigatus [11]. SNA is characterized by the formation of superficial mucosal fungal plaques within the nasal cavity and/or frontal sinus, associated with a severe mucosal inflammatory response and a local destruction of nasal bone [12]. As the disease usually affects systemically healthy dogs, and A. fumigatus is a ubiquitous fungus, a local immune deficiency in affected dogs has been suggested [13].

The clinicopathological features of SNA are similar to those of human chronic erosive non-invasive fungal sinusitis [14]. Although TLRs have not been studied in this type of sinusitis in people, they have been better characterized in chronic rhinosinusitis (CRS) including 
fungal CRS, and some forms of aspergillosis. Pathogenesis of the CRS complex remains unclear, but association of this disease with TLR polymorphisms, particularly TLR2 SNPs, has been described [15].

Association between TLR SNPs and incidence of various forms of human Aspergillus infection have been reported. A significant association between the incidence of invasive aspergillosis (IA) in recipients of transplanted allogeneic stem cells and the presence of some TLR4 SNPs in donors has been reported [16,17]. Hence, Carvalho et al. [10] have described an increased frequency of chronic pulmonary aspergillosis among TLR4 SNP carriers. In the same study, a SNP in TLR9 was shown to predispose to the allergic form of pulmonary aspergillosis.

Polymorphisms in TLR genes have not yet been described in dogs with SNA, but alteration in these receptors could hamper their function, therefore disrupting the recognition of fungi, eventually leading to fungal escape from immune surveillance. Recently, up-regulation of TLR2, 4 and 9 mRNA expression has been reported in the nasal mucosa of affected dogs [18]. Comparison of the canine and human TLR genetic sequences show a high degree of homology [19]; suggesting the polymorphisms in TLR genes found in people with aspergillosis and/or fungal CRS might also be observed in dogs.

A retrospective analysis of the medical records at the Veterinary Clinic of the University (CVU) of Liège (Belgium) over the last 5 years revealed four predominant canine breeds diagnosed with SNA: Golden Retriever, Labrador Retriever, Rottweiler and Beauceron Sheepdog. A candidate gene approach was used to test the hypothesis that SNPs in TLR2, 4 and 9 genes were associated with canine SNA. The presence of non-synonymous SNPs in the coding regions of the TLR2, 4 and 9 genes was investigated by direct sequencing of PCR-amplified products from these regions, using DNA from nine dogs with SNA belonging to various breeds (including the four aforementioned breeds). Secondly, a combination of allele-specific primers and Taq-man probe-based PCR genotyping was applied to samples from affected and control dogs derived from these four breeds in order to assess the significance of these SNPs in canine SNA.

\section{Results}

\section{Selection of single nucleotide polymorphisms}

The initial part of the study focused on a mutational analysis of TLR2, 4 and 9 genes in nine dogs with SNA belonging to various breeds. This analysis revealed two non-synonymous SNPs in the coding region of TLR2: C137A (rs22410121) and C1547T (not reported in the canine genome database). Eight non-synonymous SNPs were identified in the TLR4 exons: T23C (not reported in the canine genome database but described by Kathrani et al. [20]), C107T (not reported previously), T500C (rs22145736), A600C (rs22189454), A688G (rs22189456), G1039A (not reported in the canine genome database but described by Kathrani et al. [20]), A1571T (rs22124023) and G1807A (rs22123995). Four non-synonymous SNPs were identified in TLR9 exon: G1138A (not reported previously), $A 1372 C$ (not reported previously), A2158G (rs22882109) and G2927A (not reported previously).

All non-synonymous SNPs identified resulted in a change in the class of amino acid coded (Table 1).

\section{SNP genotyping and association study}

To assess the significance of the identified SNPs, the allelic frequencies in a group of dogs with SNA belonging to four breeds commonly affected by SNA (Golden Retriever, Labrador Retriever, Rottweiler and Beauceron Sheepdog) were compared with those found in control dogs of the same breeds (Table 2), and no significant difference was found. Two SNPs (TLR2 C1547T and TLR4 T500C) were found monomorphic between and within samples from the four selected breeds.

The same analysis was conducted within the four breed groups separately. Again, the allelic differences, although variable across breeds, were not related to the disease phenotype (Tables 3, 4, 5 and 6). In Golden Retrievers, the TLR4 C107T SNP was not found, and the least common alleles for all breeds taken together for TLR9 A1372C and TLR9 A2158G were the most common in this breed. In Golden Retrievers, the association of the C137A SNP with the disease almost reached significance. In the Labrador Retriever dogs, the least common alleles

Table 1 Amino acid change coded by non-synonymous single nucleotide polymorphisms in the canine TLR2, 4 and 9 genes

\begin{tabular}{|c|c|c|c|}
\hline Gene & SNP (accession number) & $\begin{array}{l}\text { Amino acid } \\
\text { wild type }\end{array}$ & $\begin{array}{l}\text { Amino acid change } \\
\text { associated with SNP }\end{array}$ \\
\hline \multirow[t]{2}{*}{ TLR2 } & C137A (rs22410121) & Serine & Tyrosine \\
\hline & C1547T & Serine & Leucine \\
\hline \multirow[t]{8}{*}{ TLR4 } & T23C & Valine & Alanine \\
\hline & C107T & Threonine & Isoleucine \\
\hline & T500C (rs22145736) & Leucine & Proline \\
\hline & A600C (rs22189454) & Histidine & Glutamine \\
\hline & A688G (rs22189456) & Lysine & Glutamic acid \\
\hline & G1039A & Alanine & Threonine \\
\hline & A1571T (rs22124023) & Glutamic acid & Valine \\
\hline & G1807A (rs22123995) & Glutamic acid & Lysine \\
\hline \multirow[t]{4}{*}{ TLR9 } & G1138A & Glutamic acid & Lysine \\
\hline & A1372C & Threonine & Proline \\
\hline & A2158G (rs22882109) & Serine & Glycine \\
\hline & G2927A & Arginine & Histidine \\
\hline
\end{tabular}


Table 2 Single nucleotide polymorphism allele association with sino-nasal aspergillosis dogs

\begin{tabular}{|c|c|c|c|c|}
\hline SNP & $\begin{array}{l}\text { Minor } \\
\text { allele }\end{array}$ & $\begin{array}{l}\text { Minor allele } \\
\text { frequency in the } \\
31 \text { SNA dogs }\end{array}$ & $\begin{array}{l}\text { Minor allele } \\
\text { frequency in the } \\
31 \text { CTL dogs }\end{array}$ & $p$ value \\
\hline TLR2 C137A & C & 0.42 & 0.48 & 0.47 \\
\hline TLR2 C1547T & $T$ & 0 & 0 & NA \\
\hline TLR4 T23C & $T$ & 0.40 & 0.40 & 1 \\
\hline TLR4 C107T & $T$ & 0.03 & 0 & 0.15 \\
\hline TLR4 T500C & C & 0 & 0 & NA \\
\hline TLR4 A600C & C & 0.48 & 0.43 & 0.59 \\
\hline TLR4 A688G & $A$ & 0.47 & 0.43 & 0.71 \\
\hline TLR4 G1039A & $A$ & 0.34 & 0.34 & 1 \\
\hline TLR4 A1571T & $A$ & 0.13 & 0.10 & 0.57 \\
\hline TLR4 G1807A & G & 0.13 & 0.10 & 0.57 \\
\hline TLR9 G1138A & $A$ & 0.06 & 0.05 & 0.70 \\
\hline TLR9 A1372C & $A$ & 0.50 & 0.37 & 0.15 \\
\hline TLR9 A2158G & G & 0.55 & 0.43 & 0.21 \\
\hline TLR9 G2927A & $A$ & 0.03 & 0 & 0.15 \\
\hline
\end{tabular}

Statistical significance was set at $\mathrm{P}<0.05$.

for all breeds taken together for TLR2 C137A, TLR4 A600C, TLR4 A688G, TLR4 and G1039A were most common. In Rottweiler dogs, TLR4 C107T, TLR4 A1571T, TLR4 G1807A, TLR9 G1138A and TLR9 G2927A SNPs were absent, and the least common allele for all breeds taken together for TLR4 A600C was the most common

Table 3 Single nucleotide polymorphism allele association with sino-nasal aspergillosis Golden Retriever dogs

\begin{tabular}{|c|c|c|c|c|}
\hline SNP & $\begin{array}{l}\text { Minor } \\
\text { allele }\end{array}$ & $\begin{array}{l}\text { Minor allele } \\
\text { frequency in } \\
\text { the SNA Golden } \\
\text { Retriever dogs }\end{array}$ & $\begin{array}{l}\text { Minor allele } \\
\text { frequency in } \\
\text { the CTL Golden } \\
\text { Retriever dogs }\end{array}$ & $p$ value \\
\hline TLR2 C137A & $C$ & 0.15 & 0.45 & 0.08 \\
\hline TLR2 C1547T & $T$ & 0 & 0 & 1 \\
\hline TLR4 T23C & $T$ & 0.35 & 0.40 & 1 \\
\hline TLR4 C107T & $T$ & 0 & 0 & 1 \\
\hline TLR4 T500C & C & 0 & 0 & 1 \\
\hline TLR4 A600C & C & 0.30 & 0.25 & 1 \\
\hline TLR4 A688G & A & 0.30 & 0.25 & 0.10 \\
\hline TLR4 G1039A & A & 0.05 & 0.05 & 1 \\
\hline TLR4 A1571T & $A$ & 0.25 & 0.20 & 1 \\
\hline TLR4 G1807A & G & 0.25 & 0.20 & 1 \\
\hline TLR9 G1138A & $A$ & 0.05 & 0.10 & 1 \\
\hline TLR9 A1372C & C & 0.10 & 0.25 & 0.41 \\
\hline TLR9 A2158G & $A$ & 0.20 & 0.25 & 1 \\
\hline TLR9 G2927A & A & 0 & 0 & 1 \\
\hline
\end{tabular}

Statistical significance was set at $\mathrm{P}<0.05$.
Table 4 Single nucleotide polymorphism allele association with sino-nasal aspergillosis Labrador Retriever dogs

\begin{tabular}{|c|c|c|c|c|}
\hline SNP & $\begin{array}{l}\text { Minor } \\
\text { allele }\end{array}$ & $\begin{array}{l}\text { Minor allele } \\
\text { frequency in the } \\
\text { SNA Labrador } \\
\text { Retriever dogs }\end{array}$ & $\begin{array}{l}\text { Minor allele } \\
\text { frequency in the } \\
\text { CTL Labrador } \\
\text { Retriever dogs }\end{array}$ & $p$ value \\
\hline TLR2 C137A & $A$ & 0.50 & 0.37 & 0.72 \\
\hline TLR2 C1547T & $T$ & 0 & 0 & 1 \\
\hline TLR4 T23C & $T$ & 0.44 & 0.25 & 0.46 \\
\hline TLR4 C107T & $T$ & 0.06 & 0 & 1 \\
\hline TLR4 T500C & C & 0 & 0 & 1 \\
\hline TLR4 A600C & $A$ & 0.37 & 0.25 & 0.70 \\
\hline TLR4 A688G & G & 0.37 & 0.25 & 0.70 \\
\hline TLR4 G1039A & G & 0.50 & 0.31 & 0.47 \\
\hline TLR4 A1571T & $A$ & 0.12 & 0.06 & 1 \\
\hline TLR4 G1807A & G & 0.12 & 0.06 & 1 \\
\hline TLR9 G1138A & $A$ & 0.18 & 0.06 & 0.60 \\
\hline TLR9 A1372C & $A$ & 0.37 & 0.19 & 0.43 \\
\hline TLR9 A2158G & G & 0.56 & 0.37 & 0.48 \\
\hline TLR9 G2927A & A & 0.12 & 0 & 0.48 \\
\hline
\end{tabular}

Statistical significance was set at $\mathrm{P}<0.05$.

allele. In the Beauceron Sheepdogs, TLR2 C137A, TLR9 G1138A, TLR9 A2158G and TLR9 G2927A SNPs were absent, and the least common allele in all breeds taken together for TLR9 A1372C was the most common allele in this breed.

Table 5 Single nucleotide polymorphism allele association with sino-nasal aspergillosis Rottweiler dogs

\begin{tabular}{|c|c|c|c|c|}
\hline SNP & $\begin{array}{l}\text { Minor } \\
\text { allele }\end{array}$ & $\begin{array}{l}\text { Minor allele } \\
\text { frequency } \\
\text { in the SNA } \\
\text { Rottweiler dogs }\end{array}$ & $\begin{array}{l}\text { Minor allele } \\
\text { frequency } \\
\text { in the CTL } \\
\text { Rottweiler dogs }\end{array}$ & $p$ value \\
\hline TLR2 C137A & C & 0.39 & 0.17 & 0.26 \\
\hline TLR2 C1547T & $T$ & 0 & 0 & 1 \\
\hline TLR4 T23C & C & 0.44 & 0.44 & 1 \\
\hline TLR4 C107T & $T$ & 0 & 0 & 1 \\
\hline TLR4 T500C & C & 0 & 0 & 1 \\
\hline TLR4 A600C & A & 0.39 & 0.56 & 0.51 \\
\hline TLR4 A688G & A & 0.56 & 0.45 & 0.74 \\
\hline TLR4 G1039A & A & 0.56 & 0.45 & 0.74 \\
\hline TLR4 A1571T & A & 0 & 0 & 1 \\
\hline TLR4 G1807A & G & 0 & 0 & 1 \\
\hline TLR9 G1138A & A & 0 & 0 & 1 \\
\hline TLR9 A1372C & A & 0.06 & 0.06 & 1 \\
\hline TLR9 A2158G & G & 0.06 & 0.06 & 1 \\
\hline TLR9 G2927A & A & 0 & 0 & 1 \\
\hline
\end{tabular}

Statistical significance was set at $\mathrm{P}<0.05$. 


\begin{tabular}{|c|c|c|c|c|}
\hline SNP & $\begin{array}{l}\text { Minor } \\
\text { allele }\end{array}$ & $\begin{array}{l}\text { Minor allele } \\
\text { frequency in the } \\
\text { SNA Beauceron } \\
\text { Sheepdogs }\end{array}$ & $\begin{array}{l}\text { Minor allele } \\
\text { frequency in the } \\
\text { CTL Beauceron } \\
\text { Sheepdogs }\end{array}$ & $p$ value \\
\hline TLR2 C137A & $A$ & 0 & 0 & 1 \\
\hline TLR2 C1547T & $T$ & 0 & 0 & 1 \\
\hline TLR4 T23C & $T$ & 0.12 & 0.37 & 0.57 \\
\hline TLR4 C107T & $T$ & 0.12 & 0 & 1 \\
\hline TLR4 T500C & C & 0 & 0 & 1 \\
\hline TLR4 A600C & C & 0.37 & 0.25 & 1 \\
\hline TLR4 A688G & $A$ & 0.37 & 0.25 & 1 \\
\hline TLR4 G1039A & A & 0.25 & 0.12 & 1 \\
\hline TLR4 A1571T & $A$ & 0.12 & 0.12 & 1 \\
\hline TLR4 G1807A & G & 0.12 & 0.12 & 1 \\
\hline TLR9 G1138A & A & 0 & 0 & 1 \\
\hline TLR9 A1372C & C & 0.25 & 0.50 & 0.61 \\
\hline TLR9 A2158G & $A$ & 0 & 0.37 & 0.20 \\
\hline TLR9 G2927A & A & 0 & 0 & 1 \\
\hline
\end{tabular}

Statistical significance was set at $\mathrm{P}<0.05$.

\section{Discussion}

The present study investigated the association between SNPs in TLR2, 4 and 9 genes, and the risk of developing SNA in dogs. In the first part of the study, sequencing of the coding regions of these genes in nine dogs with SNA (from various breeds) revealed two, eight and four nonsynonymous SNPs in the coding region of TLR2, TLR4, and TLR9 genes, respectively. In the second part of the study, no association was found between these SNPs and the presence of SNA.

Some of the SNPs identified in the first part of the study were not found in samples from the four breeds of dog genotyped in the second part, and minor allele frequencies varied extensively between breeds, with some uncommon alleles in one breed becoming the most common alleles in the other, and vice versa. This supports a wide genetic variations between canine breeds [21].

The only result close to significance was found for TLR2 C137A SNP in the Golden Retrievers. Due to the unpredictable direction of allelic frequency shift between dogs with SNA and controls, PLINK software was used to compute two-tailed Fisher's exact test $p$-values. Using a one tailed test would have led to half the actual $p$-value (0.04; data not shown), thereby reaching significance. Although this might be interpreted as a significant result, the rationale for choosing a one-tailed test might be debated. Furthermore, multiple testing issues (i.e. performing several tests) could be considered, leading to a lowered significance threshold that would make this result not significant. On the other hand, the power of the test might be low due to the relatively small size of the sample. Therefore, this SNP could merit further investigation with a larger number of dogs.

Although some researchers have studied the association between TLR SNPs in human CRS and some fungal diseases, the results are heterogeneous and sometimes contradictory. Several researchers have shown a significant association between TLR4 and/or TLR9 SNPs and the incidence of several forms of aspergillosis [10,16,17]; however, another study failed to associate these polymorphisms with that disease. Recently, Carvalho et al. noted a positive association between TLR4 SNPs and fungal colonization, but not susceptibility to fungal infection [22]. Kesh et al. did not report any positive association of recipient or donor TLR4 SNPs with the incidence of IA in patients undergoing allogeneic stem cell transplantation [23]. In human CRS, there are also discrepancies between studies regarding the role of SNPs in TLR genes. Park et al. reported an association between TLR2 SNPs in a Korean population [15], but Tewfik et al. could not confirm these results in Quebec [24].

The effect of the environment on susceptibility to certain diseases is another important aspect that should be considered together with genetic background. Vercelli [25] reported that genes and environment are intertwined in complex nonlinear relationships. Therefore, the same genetic background may result in the expression of different phenotypes when exposed to different environments. Consequently, in a disease with a complex pathogenesis, the genotype of multiple contributing genes, together with environmental factors, may modify the likelihood of an individual developing the disease. In such instances, individual gene mutations are insufficient to cause the disease on their own [26].

There are several limitations to the present study. Firstly, although we cannot confirm an association between polymorphism in the TLR2, 4 and 9 genes with SNA, it is possible that because of the small size of the study population, a slight/weak but real contribution of TLR2, 4 or 9 SNPs has been missed. Another potential limitation is the selection of control dogs. Although efforts were made to exclude dogs with respiratory, inflammatory, immune-mediated, neoplastic or infectious diseases, the possibility cannot be excluded that these dogs might develop such disease later in life. Nevertheless, to try to overcome this problem, we recruited only dogs older than 6 years. Another limitation was the use of a candidate gene approach, which permits comparison of allele frequencies of SNPs in genes suspected to be involved in SNA among dogs with the disease and others without (controls), but this method precludes finding other genes of interest. Genome-wide approaches would overcome this limitation, but the need for a large number of affected dogs and the high associated expense renders this difficult. 


\section{Conclusions}

The findings of the present study suggest that TLR2, 4 and 9 are not implicated in the pathogenesis of SNA in dogs. However, these results are limited by the size of the study population. This does not rule out the possibility of innate immune defects contributing to the development of the disease. Other TLR genes and/or other genes involved in mucosal immunity may be important and require further investigation.

\section{Methods}

\section{Selection of single nucleotide polymorphisms}

A mutational analysis of the TLR2, 4 and 9 exons was carried out in nine dogs diagnosed with SNA in order to determine the presence of non-synonymous SNPs in the coding regions of the genes and to investigate these further in a case-control association study to determine their significance in SNA.

The nine selected dogs (aged 10 months to 14 years; median 6.7 years; 3 females and 6 males) were from various breeds: Golden Retriever $(\mathrm{n}=2)$, Labrador Retriever $(n=2)$, Rottweiler $(n=2)$, and one each of Beauceron, German Shepherd Dog and crossbreed. Diagnosis of SNA was made on the basis of physical examination, observation of intranasal fungal plaques associated with severe turbinate destruction on rhinoscopy, presence of serum antibody specific for A. fumigatus and culture of A. fumigatus from suspected lesions. A computed tomography examination of the head was performed in some dogs.

Blood stored in ethylenediaminetetraacetic acid (EDTA) or biopsy tissue from the nasal mucosa were available for each dog and were used for extraction of genomic DNA using the Macherey-Nagel NucleoSpin blood (or tissue) isolation kit (ABgene, Epsom, UK). All biological material used to perform the present study was collected for diagnostic purpose in all dogs. Nevertheless, the right to use it was obtained by owner consent.

Canine TLR2, 4 and 9 forward and reverse primers were designed via Primer 3 (http://bioinfo.ut.ee/primer30.4.0/primer3/), using the canine specific GenBank sequences, as described previously [27] (Table 7). Only primers for exon 3 were design for TLR9, because only two bases of exon 2 are coding. Primers were synthesized by
Eurogentec S.A. (Seraing, Belgium) and reconstituted in TE buffer (10 mM Tris, 1 mM EDTA, pH 8) before use.

Conventional polymerase chain reaction (PCR) was performed using Taq Platinum ${ }^{\circ}$ PCR master mix (Invitrogen, California, USA), with reactions heated to $94^{\circ} \mathrm{C}$ for $2 \mathrm{~min}$, followed by 35 cycles of $94^{\circ} \mathrm{C}$ for $25 \mathrm{sec}, 60^{\circ} \mathrm{C}$ for $25 \mathrm{sec}$ and $68^{\circ} \mathrm{C}$ for $4 \mathrm{~min}$ then a further $72^{\circ} \mathrm{C}$ for $7 \mathrm{~min}$. The PCR products obtained were separated by $2 \% \mathrm{w} / \mathrm{v}$ agarose gel electrophoresis and appropriately sized products were excised with a clean scalpel blade and purified using the Nucleospin ${ }^{\circ}$ Extract II (Macherey-Nagel, Hoerdt, France) as per the manufacturer's instructions. Gel-purified PCR products were sent to GIGA research centre in Liège, Belgium for sequencing using sequencing primers specifically designed to cover the entire sequence of the exons (Table 8).

The sequence data were compared with the caninespecific GenBank sequences using GeneStudio contig assembly editor (http://www.genestudio.com/), and nonsynonymous SNPs were identified.

\section{SNP genotyping}

The non-synonymous SNPs identified in the first part of the study were further analysed in case and control populations by genotyping.

The case group consisted of 31 dogs diagnosed with SNA (aged 10 months to 12 years; median 6.5 years; 7 females and 24 males) from four different breeds: Golden Retriever $(\mathrm{n}=10$; minimum age 10 months; maximum age 12 years; median 7 years; 1 female and 9 males), Labrador Retriever $(\mathrm{n}=8$; minimum age 1.3 years; maximum age 12 years; median 7.1 years; 2 females and 6 males), Rottweiler ( $n=9$; minimum age 3 years; maximum age 9 years; median 5 years; 2 females and 7 males) and Beauceron $(n=4$; minimum age 10 months; maximum age 10.5 years; median 2.5 years; 2 females and 2 males). Diagnosis of SNA was based on the criteria given above. These dogs were presented at the Veterinary Clinic of the University (CVU) of Liège (Belgium) between July 2007 and June 2013. During that period, a total of 72 dogs from various breeds were diagnosed with SNA at the same institution. The breeds of dogs included in the present study were the 4 most frequently encountered breeds in these 72 dogs. A Fisher's exact test was used to assess whether those

Table 7 Primers used for amplifying TLR2, 4 and 9 for sequencing

\begin{tabular}{|c|c|c|c|c|c|}
\hline Gene & Accession number & & Product length & Forward primer $\left(5^{\prime}-3^{\prime}\right)$ & Reverse primer $\left(5^{\prime}-3^{\prime}\right)$ \\
\hline TLR2 & NC_006597.3 & & 2538 & AATAAACTGTCAAAACAATCACTCA & AAGCAAGTCTGCAAAGGACA \\
\hline \multirow[t]{3}{*}{ TLR4 } & NC_006593.3 & exon 1 & 359 & ACAAAAGCCCAGAACGCTAA & TGCACAGAGAGCAGTTTTCA \\
\hline & & exon 2 & 397 & GAGAGAGGGCAGTTGAGGTG & AGATGAGGCAATGGGATCTG \\
\hline & & exon 3 & 3111 & CTGAATCTGTGGGGCTTCTT & GAGACATGAAAAATGAGAACTGGA \\
\hline TLR9 & NC_006602.3 & exon 3 & 3390 & GGAACCCTGTTGGGAGACC & TTGGGAAGGAAAGCCTGAC \\
\hline
\end{tabular}


Table 8 Additional internal sequencing primers used

\begin{tabular}{lll}
\hline Gene & Primer set & Primer sequence (5'-3') \\
\hline TLR2 & TLR2 sequencing forward & TGGTTCCTGCTCACTTCA \\
& TLR2 sequencing reverse & TGGCAAAATCAGGGAAATG \\
TLR4 & TLR4 exon 3 sequencing forward & GGTGTCCCAGGAATCATTTG \\
& TLR4 exon 3 sequencing reverse & TAGGATCTGGAGGGAGAGGG \\
TLR9 & TLR9 exon 3 sequencing forward & GTTCAGCCGGAGATGTTTT \\
& TLR9 exon 3 sequencing reverse & CCAGCTTGTATGGGACAGG \\
\hline
\end{tabular}

breeds were predisposed to the disease as compared with the general population of dogs presented to the CVU during the same period of time. The four canine breeds were proved to be predisposed to the disease $(\mathrm{p}<0,01$ in the Golden Retriever and the Rottweiler; $\mathrm{p}<0,05$ in the Labrador Retriever and the Beauceron).

The control group consisted of 31 dogs of the same breeds: Golden Retriever $(n=10$; minimum age 6 years; maximum age 14 years; median 9 years; 4 females and 6 males), Labrador Retriever ( $\mathrm{n}=8$; minimum age 9 years; maximum age 14 years; median 12 years; 3 females and 5 males), Rottweiler ( $\mathrm{n}=9$; minimum age 6 years; maximum age 8 years; median 7.8 years; 4 females and 5 males) and Beauceron $(n=4$; minimum age 8 years; maximum age 12 years; median 11 years; 1 female and 3 males), with no history or signs of respiratory disease. Inflammatory, immune-mediated, neoplastic or infectious diseases were also excluded. Twelve dogs were healthy; five were presented for laryngeal paralysis, four for degenerative osteoarthritis, three for a lipoma and two for perineal hernia. One dog each had vaginal haemorrhage, arrhythmia, anal sac impaction, hyperadrenocorticism or hypoadrenocorticism. All dogs in this group were older than 6 years of age ( 6 - 14 years; median 9 years; 15 females and 16 males). Owner consent was again obtained for each dog.

Blood stored in ethylenediaminetetraacetic acid (EDTA) was used for genomic DNA extraction using the Macherey-Nagel NucleoSpin Blood Isolation Kit (ABgene, Epsom, UK).

The allele-specific primer-based PCR was used to genotype the SNPs $[28,29]$. Briefly, allele-specific PCR primers were designed so that the 3 ' terminal nucleotide of a primer corresponded to the site of the SNPs (Table 9). An allele-specific primer matches perfectly with one allele (the specific allele) or has a $3^{\prime}$ mismatch with a non-specific allele. Because mismatched 3 ' termini are extended by Taq polymerases with much lower efficiency than correctly matched termini, the allele-specific primer preferentially amplified the specific allele. To improve the specificity of traditional allelespecific primers, we followed a modified method [30,31] in which an artificial base pair mismatch was introduced between the third and the fifth base from the 3 ' terminus to each primer (Table 9). Two positive controls were designed for each SNP, to include allele-specific target sequence (without the addition mismatch) and the common primer (forward or reverse as appropriate), to test the ability of the assay to identify the SNP (Table 9). Primers and positive controls were synthesized by Eurogentec S. A. (Seraing, Belgium) and reconstituted in TE buffer $(10 \mathrm{mM}$ Tris, 1 mM EDTA, pH 8) before use.

The allele-specific reactions were performed by quantitative PCR (qPCR) using SYBR Green I with separate reactions for each primer set (two sets per SNP). SNP genotyping was performed by comparison of $\mathrm{Ct}$ values (Figure 1) with a homozygous sample having a lower $\mathrm{Ct}$ with the specific primer set and a higher $\mathrm{Ct}$ with the non-specific one, and a heterozygous sample having approximately equal results from both assays. Each assay was optimized with the synthetic positive controls and residual DNA from the samples used in the sequencing study. The qPCR was performed using GoTaq Colourless Master Mix (Promega Corporation, Southampton, UK) in a Stratagene Mx3005P (Agilent Technologies, Stockport, Cheshire, UK) with results analysed using the MxPro Software (ver. 4.1; Agilent Technologies). Optimisation involved varying the annealing temperature (55, 60 and $65^{\circ} \mathrm{C}$ ), with and without additional $\mathrm{MgCl}_{2}$ (final concentration: 3.0 and $4.5 \mathrm{mM}$ ), to balance the $\mathrm{Ct}$ value difference between the target and non-target allele-specific PCR, and non-specific product formation with genomic DNA and water negative controls. The final reactions consisted of 200nM of each primer, $4.5 \mathrm{mM} \mathrm{Mg}$ and 1:50,000 SYBR Green I (Invitrogen) with a thermocycling protocol of incubation at $95^{\circ} \mathrm{C}$ for $2 \mathrm{~min}$ for Taq activation and then 35 cycles of $95^{\circ} \mathrm{C}$ for $15 \mathrm{sec}$ and annealing (55 or $60^{\circ} \mathrm{C}$ : Table 9) for $30 \mathrm{sec}$ during which the fluorescence data were collected. The thermocycling protocol was extended by heating samples from $75^{\circ} \mathrm{C}$ to $95^{\circ} \mathrm{C}$ in $0.5^{\circ} \mathrm{C}$ increments for $15 \mathrm{sec}$, during which time the fluorescence data were collected in order to create a melt curve. For each SNP, the two genotyping assays were run for a single DNA sample on the same plate which also included a number of additional controls including the target and non-target synthetic positive control, and $\mathrm{AE}$ buffer (negative control).

For three SNPs (TLR9 A1372C, TLR9 C2607T, TLR9 G2927A) it was not possible to genotype on the basis of $\mathrm{Ct}$ value alone because $\mathrm{Ct}$ values were too similar with both homozygous and heterozygous animals due to the presence of additional amplified products in both reactions (Figure 2). Therefore, capillary electrophoresis (QIAxcel Advanced System, QIAGEN Group, UK) using the QIAxcel DNA High Resolution Kit (QIAGEN), QX Alignment Marker $15 \mathrm{bp} / 500 \mathrm{bp}$ (QIAGEN) and QX DNA Size Marker 25-500 bp (QIAGEN) was used to 
Table 9 Allele-specific primers and positive control used for genotyping

\begin{tabular}{|c|c|c|c|}
\hline SNP & Primer & Primer sequence $\left(5^{\prime}-3^{\prime}\right)$ & Positive control \\
\hline \multicolumn{4}{|l|}{ TLR2 } \\
\hline C137A & Forward & CCGCTCCAGATCTTTGAAgTC & CCGCTCCAGATCTTTGAACTCCATGCATTGGCAACAGTGACCTTCGGGATT \\
\hline \multirow[t]{2}{*}{$(110 \mathrm{bp})\left[60^{\circ} \mathrm{C}\right]$} & & CCGCTCCAGATCTTTGAAgTA & CCGCTCCAGATCTTTGAACTACATGCATTGGCAACAGTGACCTTCGGGATT \\
\hline & Reverse & AATCCCGAAGGTCACTGTTG & \\
\hline C1547T & Forward & GCCTCCTTCTTACCCACCTT & \\
\hline \multirow[t]{2}{*}{ (81 bp) $\left[60^{\circ} \mathrm{C}\right]$} & Reverse & GGAATCCAGTTGCTCCTaCG & GGAATCCAGTTGCTCCTTCGAGAAAGAATTTGTAAGGTGGGTAAGAAGGAGGC \\
\hline & & GGAATCCAGTTGCTCCTACA & GGAATCCAGTTGCTCCTTCAAGAAAGAATTTGTAAGGTGGGTAAGAAGGAGGC \\
\hline \multicolumn{4}{|l|}{ TLR4 } \\
\hline C107T & Forward & GGAAAGGAGAGAGGGCAGTT & \\
\hline \multirow[t]{2}{*}{ (101 bp) $\left[60^{\circ} \mathrm{C}\right]$} & Reverse & AGCTCCATGCATTGGTAAGaAG & AGCTCCATGCATTGGTAAGTAGGCATGCACCTCAACTGCCCTCTCTCCTTTCC \\
\hline & & AGCTCCATGCATTGGTAAGaAA & AGCTCCATGCATTGGTAAGTAAGCATGCACCTCAACTGCCCTCTCTCCTTTCC \\
\hline T500C & Forward & САATCTTATCСАТТССТТСАСCT & CAATCTTATCCATTCCTTCAAGCTTGCGTATTTCTCTAACATGCCCAACCTGGAG \\
\hline \multirow[t]{2}{*}{$(58 \mathrm{bp})\left[60^{\circ} \mathrm{C}\right]$} & & CAATCTTATCCATTCCTTCAACCC & CAATCTTATCCATTCCTTCAAGCCTGCGTATTTCTCTAACATGCCCAACCTGGAG \\
\hline & Reverse & CTCCAGGTTGGGCATGTTAG & \\
\hline A600C & Forward & CTAACATGCCCAACCTGGAG & \\
\hline \multirow[t]{2}{*}{$(110 \mathrm{bp})\left[60^{\circ} \mathrm{C}\right]$} & Reverse & TAAAGAAAGGTTGAGTAGTGGCtTT & TAAAGAAAGGTTGAGTAGTGGCATTTGATGTAGACGTTCTCCAGGTTGGGCATGTTAG \\
\hline & & TAAAGAAAGGTTGAGTAGTGGCtTG & TAAAGAAAGGTTGAGTAGTGGCATGTGATGTAGACGTTCTCCAGGTTGGGCATGTTAG \\
\hline A688G & Forward & GGTTCCTTTAAAGAAATTAAACTCgATA & GGTTCCTTTAAAGAAATTAAACTCCATAAACTGACTTTGAGAAGCCAGCCAGACCTTGAATA \\
\hline \multirow[t]{2}{*}{ (97 bp) $\left[60^{\circ} \mathrm{C}\right]$} & & GGTTCCTTTAAAGAAATTAAACTCgATG & GGTTCCTTTAAAGAAATTAAACTCCATGAACTGACTTTGAGAAGCCAGCCAGACCTTGAATA \\
\hline & Reverse & AGCCAGCCAGACCTTGAATA & \\
\hline G1039A & Forward & ATGGCAACGGTTGGAAATAG & \\
\hline \multirow[t]{2}{*}{$(66 \mathrm{bp})\left[60^{\circ} \mathrm{C}\right]$} & Reverse & AGAGAGTCCAGCTCCCAaGC & AGAGAGTCCAGCTCCCATGCCTAAGTTACAATTAACTATTTCCAACCGTTGCCAT \\
\hline & & AGAGAGTCCAGCTCCCAaGT & AGAGAGTCCAGCTCCCATGTCTAAGTTACAATTAACTATTTCCAACCGTTGCCAT \\
\hline A1571T & Forward & ATGGCTGATAATTCCTTTCC & \\
\hline \multirow[t]{2}{*}{ (163 bp) $\left[55^{\circ} \mathrm{C}\right]$} & Reverse & GGCTATTGTGACTCATATTTAaCA & GGCTATTGTGACTCATATTTATCAAGGGAGTTGTCCGGAAAGGAATTATCAGCCAT \\
\hline & & GGCTATTGTGACTCATATTTtTCT & GGCTATTGTGACTCATATTTATCTAGGGAGTTGTCCGGAAAGGAATTATCAGCCAT \\
\hline G1807A & Forward & TGGGTCAAAGACCACAGACA & \\
\hline \multirow[t]{2}{*}{ (53 bp) $\left[60^{\circ} \mathrm{C}\right]$} & Reverse & GCACACACCATTTGTTCAAgTTC & GCACACACCATTTGTTCAACTTCCACCAAGAGCTGTCTGTGGTCTTTGACCCA \\
\hline & & GCACACACCATTTGTTCAAgTTT & GCACACACCATTTGTTCAACTITCACCAAGAGCTGTCTGTGGTCTTTGACCCA \\
\hline
\end{tabular}

$\begin{array}{lll}\text { G1138A } & \text { Forward } & \text { GCGCAGACTCAACCTGTCCTT } \\ (152 \mathrm{bp})\left[55^{\circ} \mathrm{C}\right] & \text { Reverse } & \begin{array}{l}\text { GCGACTGGAGCGTGGTgTC } \\ \text { GCGACTGGAGCGTGGTgTT }\end{array} \\ \text { A1372C } & \text { Forward } & \text { GCGGCTGCCACAGGGGAGGT } \\ (95 \mathrm{bp})\left[60^{\circ} \mathrm{C}\right] & \text { Reverse } & \text { GAGCCGGGGTGCCCAGaGT } \\ & & \text { AGCCGGGGTGCCCAGaGG } \\ \text { A2158G } & \text { Forward } & \text { CTGGACCTCAGCGGCAACAG } \\ (58 \mathrm{bp})\left[60^{\circ} \mathrm{C}\right] & \text { Reverse } & \text { CGGCCAGGGCAAAAACCT } \\ & & \text { CGGCCAGGGCAAAAAcCC } \\ \text { G2927A } & \text { Forward } & \text { CTCCTGCGTGCCAGCTTCCT } \\ (113 \mathrm{bp})\left[55^{\circ} \mathrm{C}\right] & \text { Reverse } & \text { AGCCGCACATAGCGGGtGC } \\ & & \text { AGCCGCACATAGCGGGtGT }\end{array}$

GCGACTGGAGCGTGGTCTCCTTATGATAATTGAAGGACAGGTTGAGTCTGCGC GCGACTGGAGCGTGGTCTTCTTATGATAATTGAAGGACAGGTTGAGTCTGCGC

GAGCCGGGGGTGCCCAGTGTCACAGTCTGCCTCTACCTCCCCTGTGGCAGCCGC GAGCCGGGGGTGCCCAGTGGCACAGTCTGCCTCTACCTCCCCTGTGGCAGCCGC

CGGCCAGGGCAAAAAAGCTCACGAAGCCGATGCTGTTGCCGCTGAGGTCCAG CGGCCAGGGCAAAAAAGCCCACGAAGCCGATGCTGTTGCCGCTGAGGTCCAG AGCCGCACATAGCGGGAGCCTGTTGGGCCAGCAGGAAGCTGGCACGCAGGAG AGCCGCACATAGCGGGAGTCTGTTGGGCCAGCAGGAAGCTGGCACGCAGGAG 


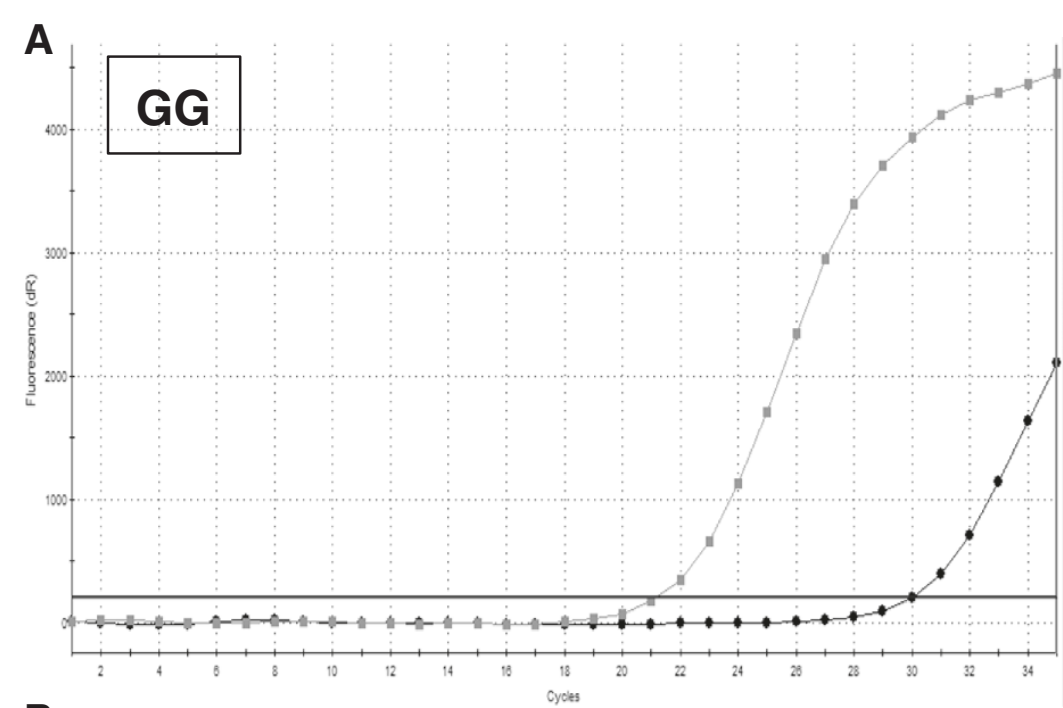

B

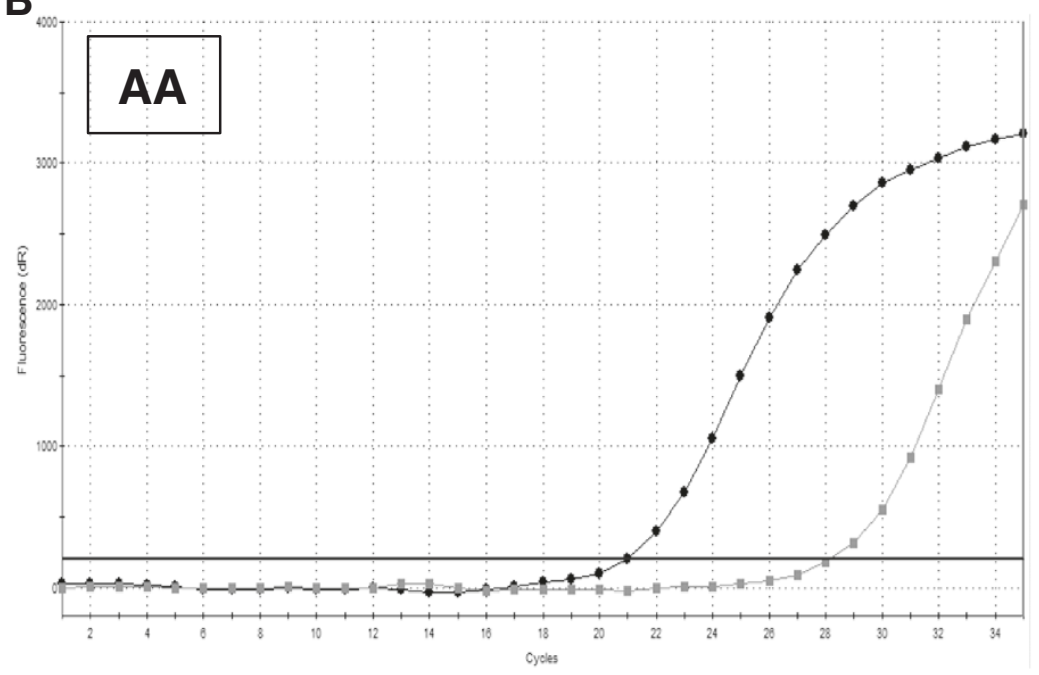

C

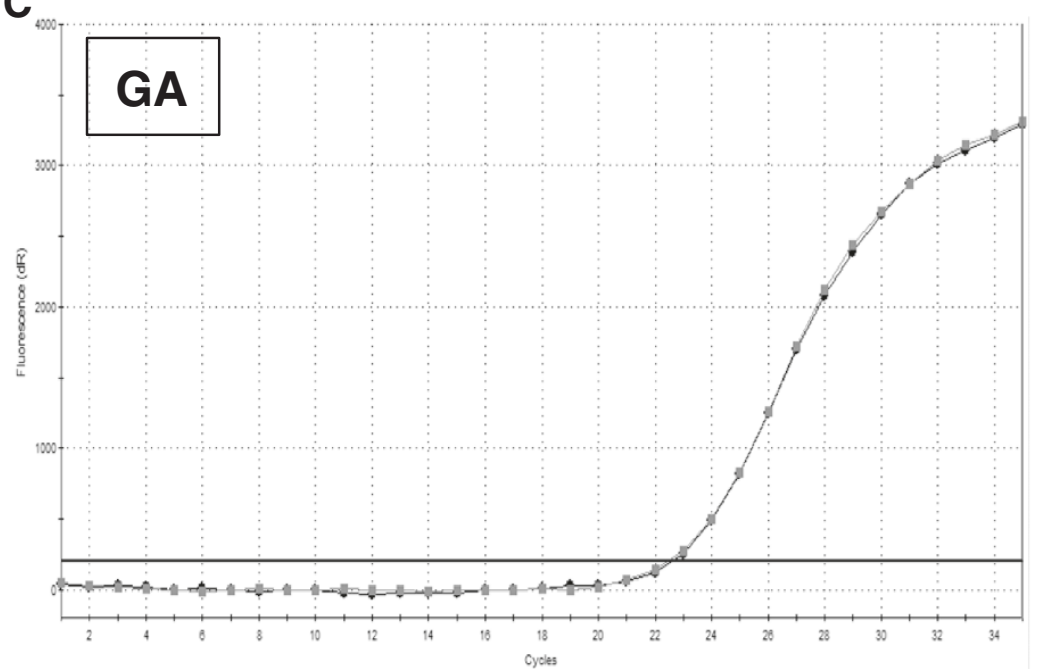

Figure 1 Real time PCR results for TLR4 A688G SNP genotyping. Figures $1 \mathbf{A}$ and $\mathbf{B}$ show the results for homozygous dogs; a lower Ct is obtained with the specific primer set and a higher $\mathrm{Ct}$ with the non-specific primer set. Figure $1 \mathbf{C}$ shows the results for a heterozygous dog; both assays give approximately equal Ct results. 


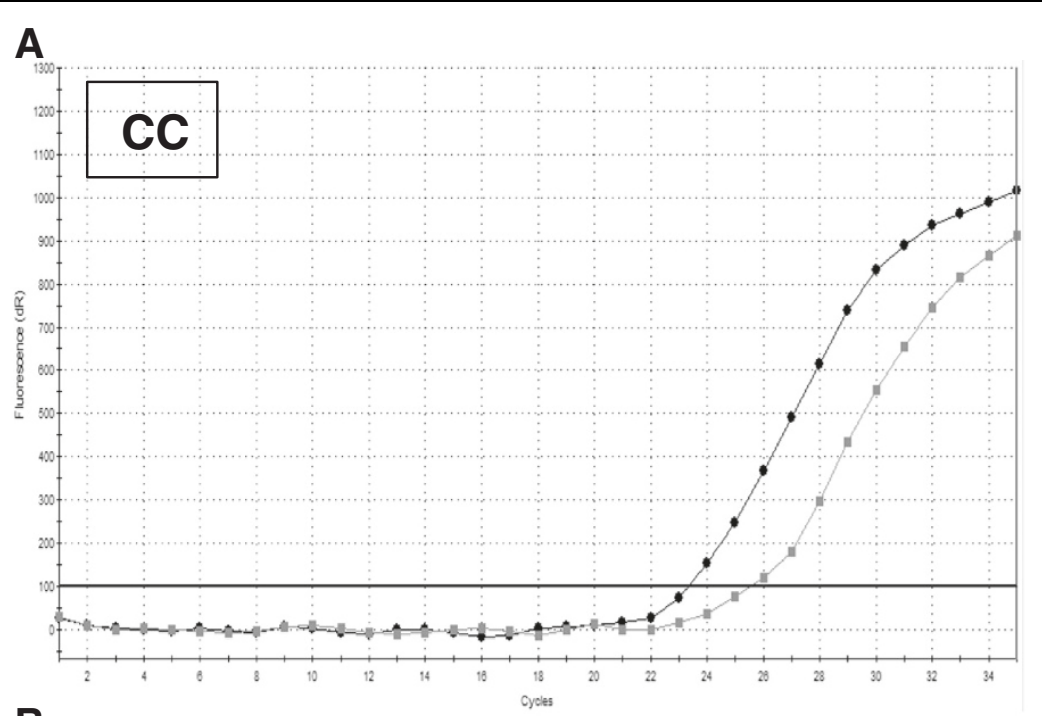

B
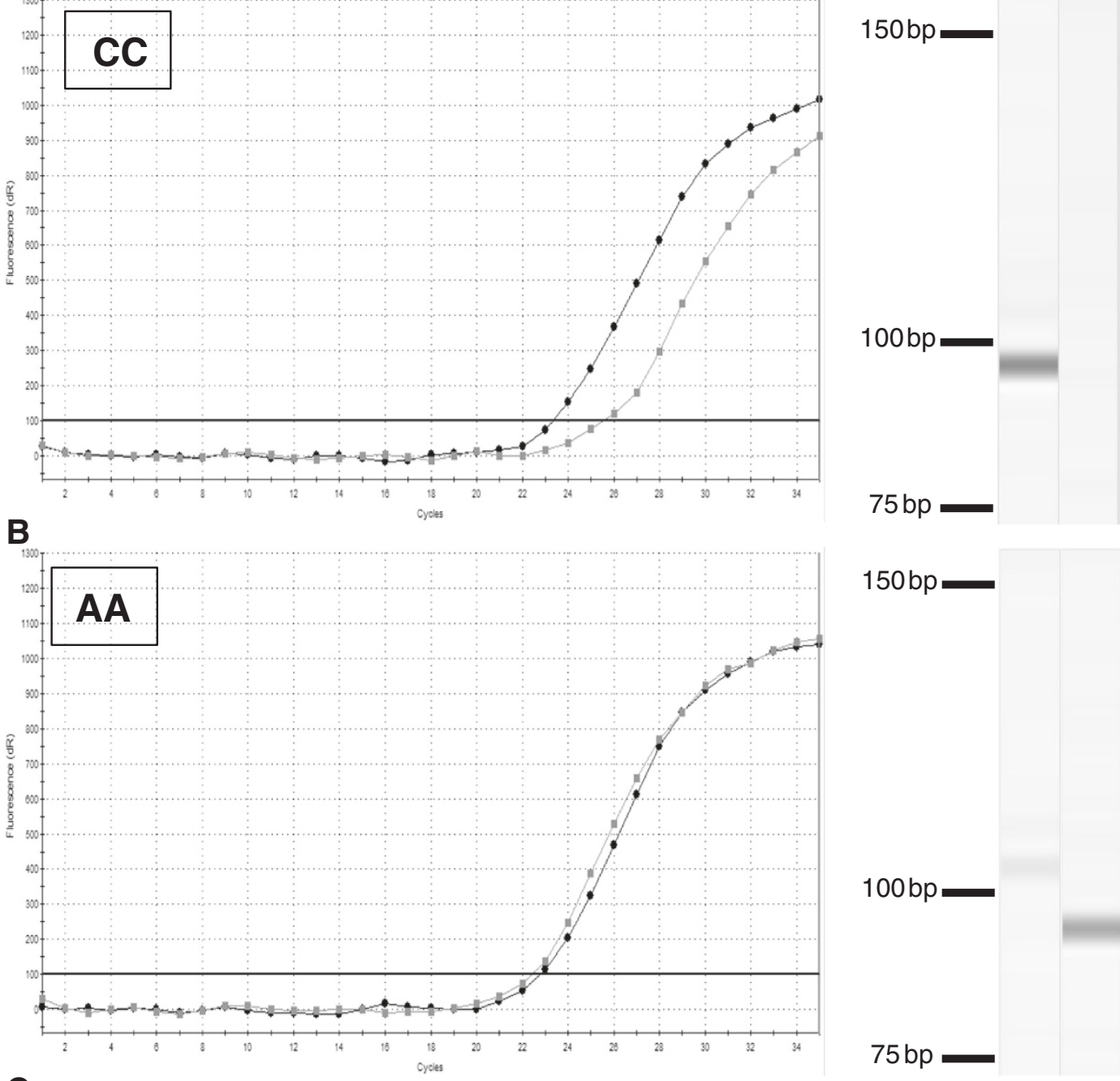

C
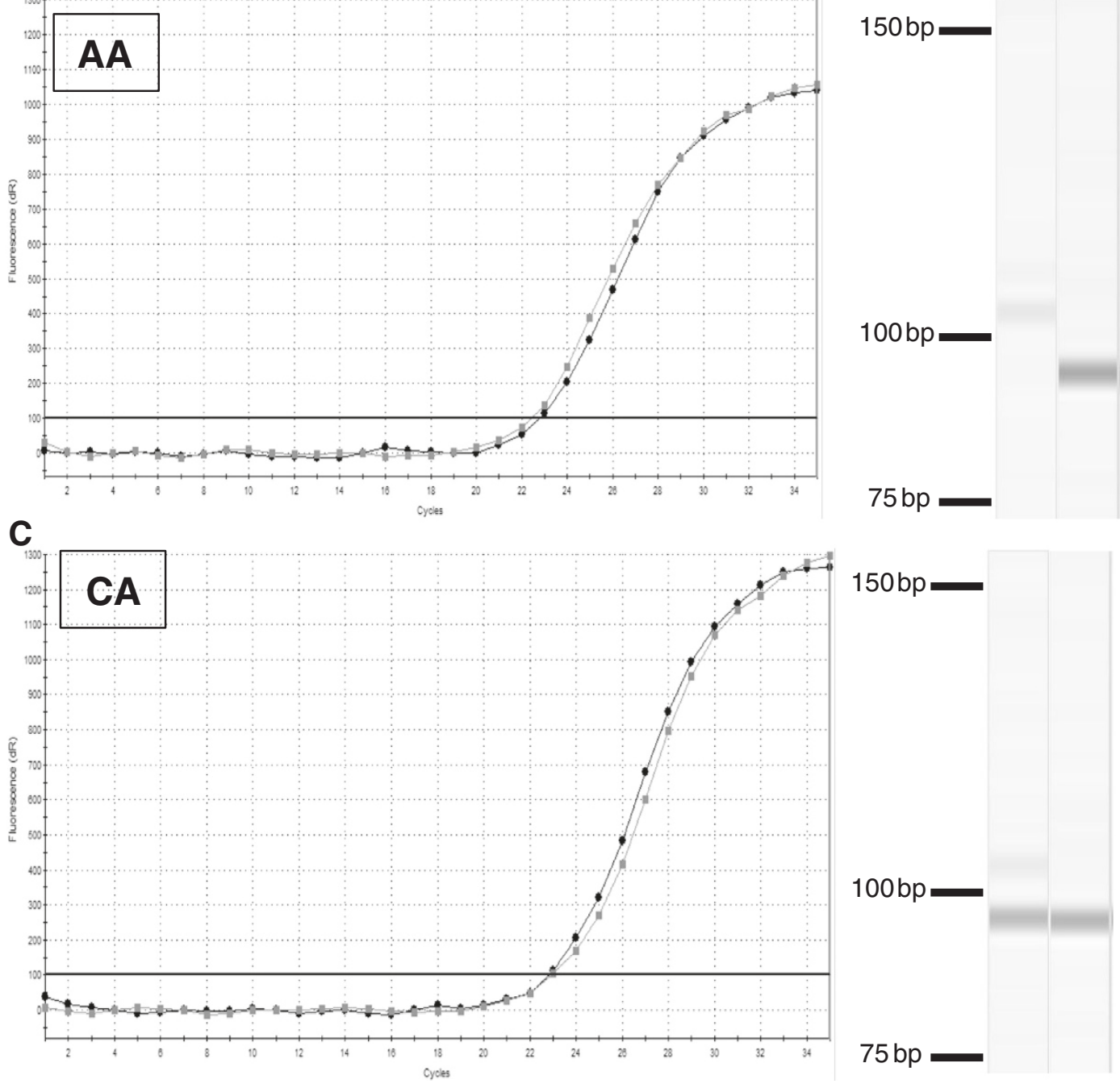

Figure 2 Real time PCR and capillary electrophoresis results for TLR9 A1372C SNP genotyping. For this SNP, genotyping was not possible on the basis of Ct value alone because Ct values were too similar with both homozygous (Figure $2 \mathbf{A}$ and $\mathbf{B}$ ) and heterozygous (Figure $2 \mathbf{C}$ ) dogs. Capillary electrophoresis of PCR products permits differentiation of the products according to their size. 
differentiate the products according to their size (Figure 2) and to genotype each sample. Samples were analysed using the QIAxcel ScreenGel Software (ver. 1.2.0; QIAGEN) and the standard DM500 analysis protocol.

For one TLR4 SNP (T23C) we could not successfully optimise a set of allele-specific primers which could successfully genotype this base position. Both primers with and without the additional artificial base pair mismatch were tried, but an assay which would amplify DNA from dogs with the $\mathrm{C}$ allele could not optimised. Therefore, a Taq-man (hydrolysis) probe-based qPCR assay was designed using Primer3 and optimised against the synthetic positive control and residual DNA from the sequencing experiments. The assay comprised a forward primer (GCACAGAAAATGCCAGAATG), reverse primer (AGGTGAACCGACATGAAACC) and two allele-specific probes (FAM-CTACCCGCCTGGCTGGGATAT-BHQ-1) and (HEX-CTACCCGCCTGGTTGGGATAT-BHQ-1). The genotyping was performed using GoTaq Colourless Master Mix (Promega) with 200nM primers, 100nM of each probe and $4.5 \mathrm{mM} \mathrm{Mg}$ in a final volume of $25 \mu \mathrm{l}$. The same thermocycling protocol was used as for the allele-specific genotyping with a $60^{\circ} \mathrm{C}$ annealing temperature, but 40 cycles were performed with genotyping based on end-point fluorescence using the MxPro software. Reactions were run in duplicate for each sample with homozygous, heterozygous and no-template controls were run with each reaction.

\section{Association study}

Statistical analysis was performed with the whole genome association analysis toolset PLINK (http://pngu. mgh.harvard.edu/ purcell/plink/). Minor allele frequencies were calculated for each SNP and case-control comparisons were analysed for all breeds together (using contingency tables and Chi-squared tests) and separately (using two-tailed Fisher exact tests). Statistical significance was set at $\mathrm{p}<0.05$.

\section{Abbreviations \\ SNA: Sino-nasal aspergillosis; SNP(s): Single nucleotide polymorphism(s); TLR(s): Toll-like receptor(s); PAMPs: Pathogen-associated molecular patterns; CRS: Chronic rhinosinusitis; IA: Invasive aspergillosis; PCR: Polymerase chain reaction; qPCR: quantitative polymerase chain reaction; $C T L$ : Control.}

\section{Competing interests}

The authors declare that they have no competing interests.

\section{Authors' contributions}

EM contributed to study design, performed the experiments, interpreted the results and wrote the manuscript. IRP contributed to study design and the experiments, helped with laboratory work and interpretation of the results and revised the final manuscript. FF helped with study design and performed the statistical analysis. RL and CC participated in the sample collection. MJD revised the final manuscript. DP supervised study design and revised the final manuscript. All the authors read and approved the final manuscript.

\section{Acknowledgements}

The authors thank Dr Gabriel, Dr Heeren, Dr Stengel, Dr Van den Brande and Dr Van Vliet for their contribution to sample collection.

\section{Author details}

'Department of Veterinary Clinical Sciences, Division of Companion Animal Internal Medicine, Faculty of Veterinary Medicine, University of Liège, Sart Tilman, Liège 4000, Belgium. ${ }^{2}$ Molecular Testing, TDDS Itd., The Innovation Centre, University of Exeter, Exeter, UK. ${ }^{3}$ Biostatistics, Bioinformatics and Animal Selection, Department of Animal Production, Faculty of Veterinary Medicine, University of Liège, Sart Tilman, Liège 4000, Belgium. ${ }^{4}$ Department of Clinical Sciences, University of Toulouse, INP, National Veterinary School of Toulouse, Toulouse cedex 03 31076, France. ${ }^{5}$ School of Veterinary Sciences,

University of Bristol, Langford House, Langford, Bristol BS40 5DU, UK.

Received: 5 December 2013 Accepted: 11 August 2014

Published: 16 August 2014

\section{References}

1. Ooi EH, Wormald PJ, Tan LW: Innate immunity in the paranasal sinuses: a review of nasal host defenses. Am J Rhinol 2008, 22(1):13-19.

2. Vroling $A B$, Fokkens WJ, van Drunen $C M$ : How epithelial cells detect danger: aiding the immune response. Allergy 2008, 63(9):1110-1123.

3. Schroder NW, Schumann RR: Single nucleotide polymorphisms of Toll-like receptors and susceptibility to infectious disease. Lancet Infect Dis 2005, 5(3):156-164.

4. Braedel S, Radsak M, Einsele H, Latgé J-P, Michan A, Loeffler J, Haddad Z, Grigoleit $U$, Schild $H$, Hebart $H$ : Aspergillus fumigatus antigens activate innate immune cells via toll-like receptors 2 and 4 . Br J Haematol 2004, 125(3):392-399.

5. Mambula SS, Sau K, Henneke P, Golenbock DT, Levitz SM: Toll-like receptor (TLR) signaling in response to Aspergillus fumigatus. J Biol Chem 2002, 277(42):39320-39326.

6. Meier A, Kirschning CJ, Nikolaus T, Wagner H, Heesemann J, Ebel F: Toll-like receptor (TLR) 2 and TLR4 are essential for Aspergillus-induced activation of murine macrophages. Cell Microbiol 2003, 5(8):561-570.

7. Romani L: Immunity to fungal infections. Nat Rev Immunol 2004 , 4(1):1-23

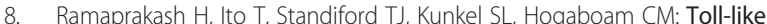
receptor 9 modulates immune responses to Aspergillus fumigatus conidia in immunodeficient and allergic mice. Infect Immun 2009, 77(1):108-119.

9. Ramirez-Ortiz ZG, Specht CA, Wang JP, Lee CK, Bartholomeu DC, Gazzinelli RT, Levitz SM: Toll-like receptor 9-dependent immune activation by unmethylated CpG motifs in Aspergillus fumigatus DNA. Infect Immun 2008, 76(5):2123-2129.

10. Carvalho A, Pasqualotto AC, Pitzurra L, Romani L, Denning DW, Rodrigues F: Polymorphisms in toll-like receptor genes and susceptibility to pulmonary aspergillosis. J Infect Dis 2008, 197(4):618-621.

11. Sharp NJH, Harvey CE, O'Brien JA: Treatment of canine nasal aspergillosis/ penicilliosis with fluconazole (UK-49,858). J Small Anim Pract 1991, 32(10):513-516.

12. Peeters D, Clercx C: Update on canine sinonasal aspergillosis. Vet Clin North Am Small Anim Pract 2007, 37(5):901-916. vi.

13. Peeters D, Peters IR, Clercx C, Day MJ: Quantification of mRNA encoding cytokines and chemokines in nasal biopsies from dogs with sino-nasal aspergillosis. Vet Microbiol 2006, 114(3-4):318-326.

14. Day MJ: Canine sino-nasal aspergillosis: parallels with human disease. Med Mycol 2009, 47(s1):S315-S323.

15. Park CS, Cho JH, Park YJ: Toll-like receptor 2 gene polymorphisms in a Korean population: association with chronic rhinosinusitis. Otolaryngo Head Neck Surg 2011, 144(1):96-100

16. Bochud PY, Chien JW, Marr KA, Leisenring WM, Upton A, Janer M, Rodrigues SD, Li S, Hansen JA, Zhao LP, Aderem A, Boeckh M: Toll-like receptor 4 polymorphisms and aspergillosis in stem-cell transplantation. N Engl J Med 2008, 359(17):1766-1777.

17. de Boer MG, Jolink $H_{\text {, Halkes }} \mathrm{C}$, van der Heiden PL, Kremer D, Falkenburg JH,

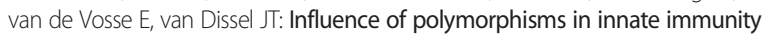
genes on susceptibility to invasive aspergillosis after stem cell transplantation. PLOS ONE 2011, 6(4):e18403. 
18. Mercier E, Peters IR, Day MJ, Clercx C, Peeters D: Toll- and NOD-like receptor mRNA expression in canine sino-nasal aspergillosis and idiopathic lymphoplasmacytic rhinitis. Vet Immunol Immunopathol 2012, 145(3-4):618-624.

19. Jungi TW, Farhat K, Burgener IA, Werling D: Toll-like receptors in domestic animals. Cell Tissue Res 2011, 343(1):107-120

20. Kathrani A, House A, Catchpole B, Murphy A, German A, Werling D, Allenspach K: Polymorphisms in the TLR4 and TLR5 gene are significantly associated with inflammatory bowel disease in German shepherd dogs. PLOS ONE 2010, 5(12):e15740.

21. Irion DN, Schaffer AL, Famula TR, Eggleston ML, Hughes SS, Pedersen NC: Analysis of genetic variation in 28 dog breed populations with 100 microsatellite markers. J Hered 2003, 94(1):81-87.

22. Carvalho A, Cunha C, Carotti A, Aloisi T, Guarrera O, Di lanni M, Falzetti F, Bistoni F, Aversa F, Pitzurra L, Rodrigues F, Romani L: Polymorphisms in Toll-like receptor genes and susceptibility to infections in allogeneic stem cell transplantation. Exp Hematol 2009, 37(9):1022-1029.

23. Kesh S, Mensah NY, Peterlongo P, Jaffe D, Hsu K, VDB M, O'Reilly R, Pamer E, Satagopan J, Papanicolaou GA: TLR1 and TLR6 polymorphisms are associated with susceptibility to invasive aspergillosis after allogeneic stem cell transplantation. Ann N Y Acad Sci 2005, 1062:95-103.

24. Tewfik MA, Bosse $Y$, Hudson TJ, Vallee-Smejda S, Al-Shemari H, Desrosiers M: Assessment of Toll-like receptor 2 gene polymorphisms in severe chronic rhinosinusitis. J Otolaryngol Head Neck Surg 2008, 37(4):552-558.

25. Vercelli D: Genetics, epigenetics, and the environment: switching buffering, releasing. J Allergy Clin Immunol 2004, 113(3):381-386. quiz 387

26. Terwilliger JD, Goring HH: Gene mapping in the 20th and 21st centuries: statistical methods, data analysis, and experimental design 2000. Hum Biol 2009, 81(5-6):663-728.

27. Peters IR, Helps CR, Hall EJ, Day MJ: Real-time RT-PCR: considerations for efficient and sensitive assay design. J Immunol Methods 2004, 286(1-2):203-217.

28. Kwok S, Kellogg DE, McKinney N, Spasic D, Goda L, Levenson C, Sninsky JJ: Effects of primer-template mismatches on the polymerase chain reaction: human immunodeficiency virus type 1 model studies. Nucleic Acids Res 1990, 18(4):999-1005.

29. Drenkard E, Richter BG, Rozen S, Stutius LM, Angell NA, Mindrinos M, Cho RJ, Oefner PJ, Davis RW, Ausubel FM: A simple procedure for the analysis of single nucleotide polymorphisms facilitates map-based cloning in Arabidopsis. Plant Physiol 2000, 124(4):1483-1492.

30. Hayashi K, Hashimoto N, Daigen M, Ashikawa I: Development of PCR-based SNP markers for rice blast resistance genes at the Piz locus. Theor Appl Genet 2004, 108(7):1212-1220.

31. Papp AC, Pinsonneault JK, Cooke G, Sadee W: Single nucleotide polymorphism genotyping using allele-specific PCR and fluorescence melting curves. Biotechniques 2003, 34(5):1068-1072.

\section{Submit your next manuscript to BioMed Central and take full advantage of:}

- Convenient online submission

- Thorough peer review

- No space constraints or color figure charges

- Immediate publication on acceptance

- Inclusion in PubMed, CAS, Scopus and Google Scholar

- Research which is freely available for redistribution 